This item was submitted to Loughborough's Research Repository by the author.

Items in Figshare are protected by copyright, with all rights reserved, unless otherwise indicated.

\title{
Measuring brand association strength: a consumer based brand equity approach
}

PLEASE CITE THE PUBLISHED VERSION

http://dx.doi.org/10.1108/03090561311324363

PUBLISHER

(C) Emerald Group Publishing Limited

VERSION

AM (Accepted Manuscript)

LICENCE

CC BY-NC-ND 4.0

\section{REPOSITORY RECORD}

French, Alan, and Gareth Smith. 2019. "Measuring Brand Association Strength: A Consumer Based Brand Equity Approach”. figshare. https://hdl.handle.net/2134/14786. 
This item was submitted to Loughborough's Institutional Repository (https://dspace.lboro.ac.uk/) by the author and is made available under the following Creative Commons Licence conditions.

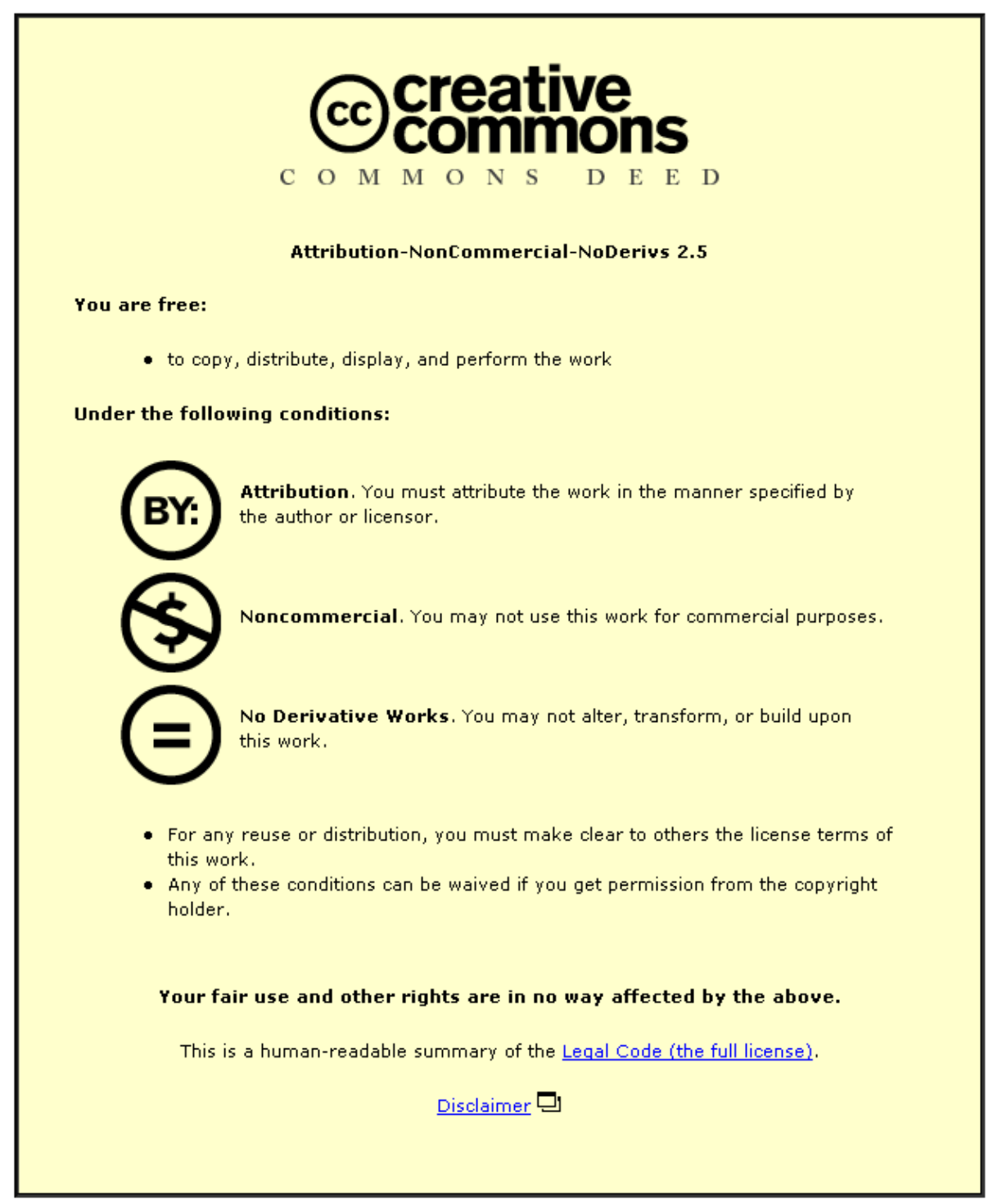

For the full text of this licence, please go to: http://creativecommons.org/licenses/by-nc-nd/2.5/ 


\title{
Measuring Brand Association Strength: A Consumer Based Brand Equity Approach
}

\author{
Alan French* and Gareth Smith** \\ *Loughborough University, UK and **Oxford Brookes University, UK
}

\section{The Authors:}

Dr Alan French, Senior Lecturer in Management Science, Loughborough University Business School, Loughborough University, Loughborough, Leicestershire LE11 3TU, UK.

Tel: +44 (0)1509 223199; fax: +44 (0)1509 223960; email: A.P.French@lboro.ac.uk

Dr Gareth Smith, Professor of Marketing, Oxford Brookes University Business School, Oxford Brookes University, Oxford, Oxfordshire.

Tel: +44 (0)1865 485741; fax: +44 (0)1865 485765; email: g.smith@brookes.ac.uk

Alan French is a Senior Lecturer in Management Science at Loughborough University, UK. He studied for his first degree and PhD at the University of East Anglia. His research focuses on the application of Management Science techniques in business and he has published in the European Journal of Marketing, Journal of the Operational Research Society and Computers and Operations Research.

Gareth Smith is a Professor of Marketing at Oxford Brookes University, UK. His research in branding covers brand personality, brand extension effects and branding in political markets. He has published on branding in the European Journal of Marketing, Journal of Marketing Management and Marketing Theory.

Classification: Research Paper 


\title{
Measuring Brand Association Strength: A Consumer Based Brand Equity Approach
}

\begin{abstract}
Purpose - To date, the brand equity literature has been limited by a gap in the measurement of a key driver of Consumer Based Brand Equity (CBBE). We address this gap by developing a new, consumer-based measure of brand association strength, a critical element of CBBE.

Design/Methodology/Approach - This paper, based on cognitive psychology, takes a recently developed brand mapping approach and uses its features, along with network analysis measures designed specifically by the authors for this particular analysis, to produce a novel measure of brand association strength.
\end{abstract}

Findings - Traditional network analysis measures (e.g. number of associations, density) neglect to take into account the underlying structure of consumers' brand associations as reflected in concept maps. We use primary research on a well-known brand (McDonald's) to show that both number of associations and a modified density measure taking account of the special structure of concept maps can be used to generate an intuitive and readily understood measure of brand association strength. Originality/Value -We develop a new measure to analyse brand association strength for any given brand. As such this paper contributes to the methodological and practical development of the CBBE construct.

Keywords - Brand Equity, Brand Association Strength, Brand Concept Mapping, Network Analysis.

\section{Introduction: Brand Equity}

Branding has become a top priority for both managers and academics with the acceptance that brands are among the most important assets that many firms possess (Ambler, 2003). Unsurprisingly this has led to an explosion of academic research into branding. Keller and Lehmann’s (2006) review paper identifies five extensive research streams within branding; brand positioning, corporate image and reputation, strategic brand management and brand growth. The fifth broad research stream, and the focus of this paper, is the assessment of brand performance, typically referred to as brand equity.

Brand equity has been defined in numerous ways though in essence all agree that it relates to the incremental value endowed by the brand to a product or service compared to an unbranded counterpart. More specifically, brand equity has been defined as "a set of brand assets and liabilities linked to a brand, its name and symbol, that add to or subtract from the value provided by a product 
or service to a firm and or to that firm's customers” (Aaker, 1991, p. 15). Brand equity is important because it relates to the value gained from the brand by the firm in terms of the following: increased efficiency and effectiveness of marketing programmes, greater customer loyalty, more resistance to competitive promotional activity, greater barriers to competitive entry and higher perceived product quality (Farquhar, 1989; Erdem, 1998; Chaudhuri and Holbrook, 2001). Brand equity is equally important to consumers because it enhances their interpretation/processing of information, increases confidence in the purchase decision and produces greater satisfaction in use (Aaker, 1996a).

Over time, three discrete research streams have defined or conceptualised the brand equity construct (Rego et al., 2009). One approach considers brand equity as differential brand performance over unbranded product performance (e.g. measuring the price premium available to a brand when compared with a generic, unbranded product's price (Aaker, 1996b)). A second approach considers brand equity as the shareholder value of the brand (e.g. the financial value of the brand after tangible and intangible assets have been accounted for (Ailawadi et al., 2003)). A third, and the most prolific research stream, conceptualises brand equity from a cognitive psychology perspective. Overall this approach has been extensively researched under the umbrella term Consumer Based Brand Equity (henceforth CBBE) (Erdem et al., 1999; del Rio et al., 2001; Keller, 2002; Netemeyer et al., 2004; Pappu et al., 2006; French and Smith, 2010). Most adopt Aaker's (1991) model of CBBE wherein brand knowledge is the core component along with perceived quality and brand loyalty as outputs developing from said knowledge (Christodoulides and de Chernatony, 2010). In this context, CBBE is defined as "the differential effect of brand knowledge on consumer response to the marketing of the brand" (Keller, 1993, p. 2). Put simply, "brand knowledge is the source of brand equity” (Keller, 2003, p. 596).

\section{Brand Association Strength and Consumer Based Brand Equity}

Keller's (1993) seminal paper on CBBE conceptualises brand knowledge as those associations about a brand recalled from memory. Likewise, Christodoulides and de Chernatony (2010) in their CBBE literature review conclude that the majority of conceptual studies identify brand associations as a core component of CBBE. The extant CBBE research extensively uses human associative memory (HAM) theory, derived from cognitive psychology (Anderson and Bower, 1973; Wyer and Srull, 1989) to conceptualise how brand association networks form and operate. The theory assumes that knowledge of a brand is stored in a consumer's memory as individual pieces of brand information which are linked together to form a complex associative network of the brand 
(Anderson, 1983a; Teichert and Schöntag, 2010). Importantly, brand information is recalled from memory by an 'activation' process when one association stimulates the recall of another, linked association (Anderson, 1983b). Activation 'spreads' from an association to another or others, producing a chain reaction and providing the “"energy' that runs the cognitive machinery” (Anderson, 1983a, p. 86). Thus, the brand name Volvo may stimulate, through spreading activation, associations such as cars, Swedish, well-built and safe. For any given brand, its associations are core to decision making (Alba et al., 1991) as consumers use them to "help process, organize and retrieve information in memory and to aid them in their purchase decisions” (Low and Lamb, 2000, p. 351).

Having identified the importance of the network of brand associations held in memory for CBBE, it is apparent that not all associations are of equal importance. Specifically, "the presence of strongly held, favourably evaluated associations that are unique to the brand and imply superiority over other brands is critical to a brand's success" (Keller, 1993, p. 6). The strength of a brand's associations is therefore a necessary condition for high CBBE. Conceptually, the stronger an association, the more likely it will be recalled from memory via the spreading activation process that underpins mental maps (Anderson, 1983b; Keller, 1993).

Despite this central role of brand associations and their relative strength for CBBE, there has to date been no attempt to operationalise directly a measurement of the strength of consumer generated associations of a brand. As such this paper's contribution is to fill this gap. It does this by providing a novel application of brand mapping to CBBE measurement. The paper then provides a generally applicable measure of brand association strength measurement from the maps, thus contributing to our knowledge on what we have shown to be a core driver of CBBE.

In addition, an important, practical contribution is that it provides tools and methods to brand managers to facilitate the task of building the equity of their brand. The brand mapping method and association strength measurement are both practical and intuitive approaches with clear, easily analysed outcomes that may be used to highlight appropriate marketing mix strategies for building brand equity.

The rest of this paper adopts the following structure. Firstly we capture brand associations through brand mapping and then evaluate the literature on the measurement of brand association strength within these maps. Next we produce two comparative maps for McDonald's, one based on respondents positive towards the brand, the other for those negative towards the brand. We then 
develop our measure of brand association strength before illustrating its application to McDonald's. We conclude with a discussion of the findings, practical applications and how the measure of brand association strength may be developed further by future research.

\section{Components of Brand Association Strength within Brand Concept Maps}

It is the spreading activation process from a brand name to brand associations recalled from memory which produces a mental map of the brand (Dobni and Zinkhan, 1990; John et al., 2006). As such, mental maps of brand associations reflect the structure of consumer memory on which CBBE is based. Qualitative methods can produce individual brand maps but these cannot be aggregated to allow for generalisation to the wider population and so are of limited value. Quantitative techniques for mapping associations, often referred to as perceptual mapping, include multi-dimensional scaling, correspondence analysis etc. (see Gower et al. (2010) for an overview). However, these approaches do not directly replicate the mental map consumers have for the brand. This methodological gap was filled recently by a brand concept mapping (BCM) approach (John et al., 2006) based on the HAM conceptualisation referred to previously. The maps produced are drawn by individual consumers based on their recalled brand associations. They can be produced in quantity, with proven validity and reliability, to allow confidence in the resulting consensus map for a given brand (i.e. a single brand map is derived from the individual, consumer drawn maps). As such, BCM encapsulates directly the complex network of associations which are the core of CBBE. Moreover, as long as the brand is known to the consumers who draw the maps, any fmcg, consumer durable, service, corporate and or product brands may use the BCM approach.

With regards the nature of brand association strength, it has been argued that the more associations that a brand map contains, the stronger the brand is as this increases the number of pathways between associations and increases the chance they will be activated/recalled (Krishnan, 1996). Also, we know that the pathways or links between associations vary in strength (Keller, 2002). The stronger the link between two associations the more likely will be spreading activation from one to the other. In addition, the cognitive structure of a brand plays an important part in the overall strength of a brand (Haugtvedt et al., 1993). In particular, "the number of links, or relationships, in a map has been identified as a measure of both the extent of an individual's knowledge and the conceptual integration and cohesion present in their representation” (Joiner, 1998, p. 315). Anderson (1983b) identifies empirically the positive network activation effect of an 'integrated' versus a 'non-integrated' associative network, suggesting also that integrated networks involve 
elaborative encoding of knowledge - i.e. the association is elaborated by the identification of its link(s) to other associations. It also allows interconnected associations to be retrieved as a whole, allowing for stronger meaning from integrated associations (Krishnan, 1996).

Another structural feature of maps is the position that associations have in a brand map, reflecting their importance to the brand. Associations directly connected to the brand, as the ideas thought of first as most descriptive of the brand, are assumed to be the strongest in defining the brand and its meaning for a consumer. Such associations are the 'essence' of the brand (van Rekom et al., 2006) as they activate a greater number of other features and are essential as a consequence (Ahn, 1998). Associations further removed from the brand are, logically, of lesser importance because they are not directly linked to the brand and are less often thought of as descriptors of the brand. As can be seen in the actual maps which follow (Figures 1 and 2), the strongest (first-order) associations are those linked to the brand directly (shaded ovals), followed by those which link strongly with them (second-order), but not the brand directly (unshaded ovals with a solid outline) and then the weakest (tertiary) associations (unshaded ovals with dashed outlines).

To summarise, the preceding literature has shown that brand association strength is a function of the number of associations, the strength of links between associations and the structure of the associative network, with those associations closest to the brand being the strongest. Our measure of brand association strength incorporates all of these elements.

\section{McDonald's Brand Maps}

Since the focus of this paper is to develop a measure of brand association strength, we do not rehearse the brand concept mapping protocol here (see John et al. (2006) for full coverage). As previously alluded to, the BCM approach is generalisable. John et al. (2006) have tested and confirmed the BCM's reliability (via a split-half test) and nomological and convergent validity. Their findings have led to subsequent generalisation of the technique to fmcg's (Nike and Sony), services (Disney and the Mayo Clinic), consumer durables (snowboarding brands) plus not for profit brands (UK political parties) (John et al., 2006; van Rekom et al., 2009; French and Smith, 2010). The BCM technique may be applied in any market sector where consumers possess associative networks of the brands therein. Nor is there any limitation to the geographic application of the method having been successfully used in the US, UK and Holland. As such, the BCM's application to the McDonalds brand in the UK is justifiable. 
The BCM method itself is uncomplicated, requiring minimal interviewer training. Maps can be completed quickly (15 to 20 minutes) and can be carried out in a variety of ways: one-to-one mall intercepts, in focus groups or with large groups. Data needs too are straightforward; the relevant brand associations have to be identified and then used in the construction of individual maps. We chose McDonald's to map because it is a universally known brand that would supply maps that would allow us to measure brand association strength. A convenience sample of 85 students at a UK university was used. The relative demographic homogeneity made this sample appropriate for our purpose, illustrating the development and testing of our measure of brand association strength (Calder et al., 1981). The respondents were also knowledgeable about, and a key consumer group for, the brand. McDonald's associations were elicited from a student sample of similar composition $(\mathrm{N}=101)$ and this process identified 30 associations for subsequent use in map building. Individual maps were then aggregated into consensus maps (as per the BCM protocol, (John et al., 2006)). Specifically we produced two maps for the brand; one of those for respondents with a positive attitude towards McDonald's (Figure 1), the other for those with a negative attitude (Figure 2) (51 positive and 34 negative maps). Research has shown that "consumers are likely to differ in the number of associations stored in memory for a marketing object, the content of these associations, and their structure” (Joiner, 1998, p. 314). It has been shown (Kirmani et al., 1999) that those with a positive attitude towards the brand will have stronger brand associations, resulting from recent experience of/consumption of the brand and exposure to more brand associations in the process, than those negative to the brand. This, we postulated, would allow us to measure the differing strength of the associations held in the respective consensus maps.

TAKE IN FIGURES 1 AND 2 ABOUT HERE.

\section{Measuring Brand Association Strength}

Concept maps are a particular form of associative networks and therefore their analysis sits within the extant network analysis literature. Notably, quantitative psychologists have developed the work of the cognitive psychologists (previously mentioned) by applying network analysis methods to the measurement of associative networks (see Knoke and Yang (2008) for an overview). These methods have been applied to the study of consumer memory networks and particularly brand networks (Ward and Reingen, 1990; Iacobucci and Hopkins, 1992; Iacobucci et al., 1996; Krishnan, 1996; Henderson et al., 1998, 2002). We draw on these methods in developing our measure of 
brand association strength.

As discussed, brand association strength is a function of the number of associations, the strength of links between associations and the structure of the associative network. We now integrate these elements into a single measure of brand association strength. Measuring the number of associations and the strength of individual links between associations is straightforward, whereas structure is more complex. Structure is a combination of the number of links present within a map, together with the nature of these links, i.e. what types of association (first-order, etc.) are being linked together. We adapt a traditional measure of the number of links within a map, i.e. density (Wasserman and Faust, 1994; Scott, 2000), to take into account both the particular structure of BCM and the strength of links between associations.

Density is measured as the proportion of concept map links out of the maximum number of links it could have. For a concept map with $\mathrm{n}$ associations and L links:

Density $=\mathrm{D}=\frac{L}{\frac{1}{2} n(n-1)}=\frac{2 L}{n(n-1)}$

For the concept maps created using the BCM approach, each link may have a weight of 1 , 2, or 3. A modification of the above allows the weightings to be taken into consideration:

Weighted Density $=\mathrm{D}_{\mathrm{w}}=\frac{L}{\frac{3}{2} n(n-1)}=\frac{2 L}{3 n(n-1)}$

For both density measures, a value of 0 represents a network with no links, whereas a value of 1 represents the case where all possible links are present. These measures take no account of the structure of the map. In particular, BCM have a special structure; firstly, BCM clearly distinguish the importance of different types of association (first-order, etc.) and secondly, only first-order associations can be directly connected to the brand - reducing the number of potential links.

The measure presented below takes into account the underlying structure of concept maps by drawing distinctions between the types of associations (first-order, etc.) and hence the links between them. The different types of link in terms of decreasing importance are shown in Table 1 . The weights of each link are taken into account - hence the multiplier of 3 for the maximum number of 
links of each type.

\begin{tabular}{|l|l|l|c|c|}
\hline Rank & Type & $\begin{array}{l}\text { Maximum } \\
\text { number }\end{array}$ & $\begin{array}{c}\text { Actual } \\
\text { number }\end{array}$ & Weighting \\
\hline 1 & Brand to first-order & $3 \mathrm{~F}$ & $\mathrm{~L}_{\mathrm{BF}}$ & 1 \\
\hline 2 & First-order to first-order & $3.1 / 2 \mathrm{~F}(\mathrm{~F}-1)$ & $\mathrm{L}_{\mathrm{FF}}$ & $1 / 2$ \\
\hline 3 & First-order to second-order & $3 \mathrm{~F} . \mathrm{S}$ & $\mathrm{L}_{\mathrm{FS}}$ & $1 / 3$ \\
\hline 4 & First-order to tertiary & $3 \mathrm{~F} . \mathrm{T}$ & $\mathrm{L}_{\mathrm{FT}}$ & $1 / 4$ \\
\hline 4 & Second-order to second-order & $3.1 / 2 \mathrm{~S}(\mathrm{~S}-1)$ & $\mathrm{L}_{\mathrm{SS}}$ & $1 / 4$ \\
\hline 5 & Second-order to tertiary & $3 \mathrm{~S} . \mathrm{T}$ & $\mathrm{L}_{\mathrm{ST}}$ & $1 / 5$ \\
\hline 6 & Tertiary to tertiary & $3.1 / 2 \mathrm{~T}(\mathrm{~T}-1)$ & $\mathrm{L}_{\mathrm{TT}}$ & $1 / 6$ \\
\hline
\end{tabular}

Table 1: Link Types

Where F, S and T are the number of first-order, second-order and tertiary associations respectively.

The idea of measuring the ratio between actual links and the maximum number of links possible is retained, but this ratio is evaluated for each link type. These individual ratios are then combined to produce a measure termed Structural Density. In recognition of the relative rankings, the weightings in the table above are applied to each ratio and then the weighted ratios added before dividing by the total of all the weightings to give a normalised value between 0 and 1 :

Structural Density $=\mathrm{D}_{\mathrm{S}}=$

$$
\left(\frac{1\left(\frac{L_{B}}{3 F}\right)+\frac{F}{2}\left(\frac{L_{F}}{\frac{3}{2} F(F-1)}\right)+\frac{1}{3}\left(\frac{L_{F}}{3 F}\right)+\frac{1}{4}\left(\frac{L_{F}}{S 3 F}\right)+\frac{1}{4}\left(\frac{L_{S}}{T \frac{3}{2} S(S-1)}\right)+\frac{1}{5}\left(\frac{L_{S}}{3 S}\right)+\frac{1}{6}\left(\frac{L_{T}}{\frac{3}{2} T(T-1)}\right)}{1+\frac{1}{2}+\frac{1}{3}+\frac{1}{4}+\frac{1}{4}+\frac{1}{5}+\frac{1}{6}}\right)
$$

For maps where $\mathrm{S}=0$ and/or $\mathrm{T}=0$, the associated parts of the above definition are omitted from the numerator and denominator.

For example, for the Positives map (Figure 1) $\mathrm{F}=6, \mathrm{~S}=12, \mathrm{~T}=5, \mathrm{~L}_{\mathrm{BF}}=15, \mathrm{~L}_{\mathrm{FF}}=4, \mathrm{~L}_{\mathrm{FS}}=21, \mathrm{~L}_{\mathrm{FT}}=8$, $\mathrm{L}_{\mathrm{SS}}=6, \mathrm{~L}_{\mathrm{ST}}=0, \mathrm{~L}_{\mathrm{TT}}=1$ : 


$$
\left(\frac{1\left(\frac{1}{3 \times 6}\right)+\frac{5}{2}\left(\frac{4}{\frac{3}{2} \times 6 \times 5}\right)+\frac{1}{3}\left(\frac{2}{3 \times 6 \times 1}\right)+\frac{1}{4}\left(\frac{8}{3 \times 6 \times 5}\right)+\frac{1}{4}\left(\frac{6}{\frac{3}{2} \times 1 \times 1}\right)+\frac{1}{5}\left(\frac{0}{13 \times 1 \times 5}\right)+\frac{1}{2}\left(\frac{1}{\frac{3}{2} \times 5 \times 4}\right)}{1+\frac{1}{2}+\frac{1}{3}+\frac{1}{4}+\frac{1}{4}+\frac{1}{5}+\frac{1}{6}}\right)
$$

$=0.350$. In comparison, weighted density for the same map is 0.066, meaning the Positives map contains only $6.6 \%$ of the number of links possible. However, this considers neither the differential nature of the associations, nor the special structure of a map. Structural density is able to provide a fairer assessment of the level of connectedness - in this instance 35\% of the theoretical maximum. In practice, it is extremely unlikely that a structural density value of 1 would arise - this would mean that all links were present and triple-weighted.

To put these values in context, John et al. (2006) produced two maps for a premier US-based healthcare brand (Mayo) - one for Patients and one for Non-Patients. Applying our structural density measure to these maps produces values of 0.404 (Patients) and 0.350 (Non-Patients). As Mayo and McDonald's are both well-known brands in their respective markets, it is interesting to note that the structural density values are extremely similar and would tend to suggest that values in the range 0.3 to 0.4 represent a “good” structural density score.

\section{A New Measure of Brand Association Strength}

Previous sections have highlighted the need to consider the number of associations, the nature of these associations and how they are structured. Structural density is capable of encapsulating the types of associations and how they are linked together, but is a normalised measure independent of the number of associations. In order to measure the strength of a concept map, the number of associations needs to be considered. This is done by multiplying the structural density by the number of associations. We denote our measure of brand association strength as BAS and it is defined as follows:

$\mathrm{BAS}=\mathrm{n} \cdot \mathrm{D}_{\mathrm{S}}$

Moving on to the results, the Positives map has 24 associations - McDonald's (the brand), 6 firstorder, 12 second-order and 5 tertiary, whilst the Negatives map has 16 associations (McDonald's, 6 first-order, 9 second-order, 0 tertiary). The number of links of each type (weighted) is given in Table 2. Table 3 presents the structural density and strength for the maps; weighted density values are included for the purposes of comparison. 


\begin{tabular}{|l|c|c|}
\hline Type of Link & Positives Map & Negatives Map \\
\hline Brand to first-order & 15 & 14 \\
\hline First-order to first-order & 4 & 3 \\
\hline First-order to second-order & 21 & 16 \\
\hline First-order to tertiary & 8 & 0 \\
\hline Second-order to second-order & 6 & 4 \\
\hline Second-order to tertiary & 0 & 0 \\
\hline Tertiary to tertiary & 1 & 0 \\
\hline
\end{tabular}

Table 2: Summary of Link Numbers for Positives/Negatives Maps

\begin{tabular}{|c|c|c|c|c|c|}
\hline \multicolumn{3}{|c|}{ Positives } & \multicolumn{3}{c|}{ Negatives } \\
\hline $\begin{array}{c}\text { Weighted } \\
\text { Density }\end{array}$ & $\begin{array}{c}\text { Structural } \\
\text { Density }\end{array}$ & BAS & $\begin{array}{c}\text { Weighted } \\
\text { Density }\end{array}$ & $\begin{array}{c}\text { Structural } \\
\text { Density }\end{array}$ & BAS \\
\hline 0.066 & 0.350 & 8.405 & 0.103 & 0.410 & 6.553 \\
\hline
\end{tabular}

Table 3: Comparison of Density Measures and BAS for Positives/Negatives

It is interesting to note that for those negative towards McDonald's, although they have fewer associations, those associations are stronger and better connected - as reflected by the structural density scores given in Table 3 (0.410 for Negatives and 0.350 for Positives). Given the general antipathy towards junk food and global brands, this is not an unexpected finding - they may not know as much about the brand, but they feel strongly about what they do know.

It was postulated earlier that BAS for the two maps would be different and this is borne out by the results presented in Table 3; the overall BAS value for the Positives (8.405) is higher than that for the Negatives (6.553). In theory, the BAS for Positives could have been as high as 24 (if they had achieved a structural density of 1), whilst by the same token, the Negatives BAS value could have only been as high as 16 . The larger number of associations for the Positives map gave it a higher potential BAS value than for the Negatives. Due to the structural density for the Negatives being higher than that for the Positives, the Negatives have been able to achieve proportionally more of their maximum BAS, but in absolute terms, the Positives map has greater BAS. As argued previously, it is necessary to consider both number of associations and structural density as neither is sufficient to be able to measure brand association strength effectively in isolation. 


\section{Conclusions, Limitations and Further Research}

In this paper, we have developed a measure of brand association strength which is a necessary precursor of CBBE. We show that the number of associations is insufficient to measure brand association strength; the number of associations is important, but so too is the structure (number of first-order, second-order and tertiary associations) and how these associations are linked together. We show that a new measure - structural density - can take account of the type of associations and the links between them to provide a truer reflection of the number of connections within a brand concept map. Structural density is then combined with the total number of associations to produce a measure of brand association strength, allowing two or more maps to be compared.

The maps themselves offer specific guidance to brand managers seeking to enhance CBBE. Brand managers seeking to enhance BAS may do this in the following ways: upgrading the status of important tertiary and/or second-order associations; increasing the number of associations; forging links between unconnected, but potentially valuable associations and strengthening already existing links. Any or all of these activities will enhance BAS and concomitantly CBBE. When seeking to identify which of the above options to follow, maps could be compared to competitors to look for points of parity or to highlight the presence (or absence) of USPs. For example if a Burger King map is comparatively advantaged because it shows "Convenient/Easy" directly linked to the brand, then McDonald's may develop its own associations in this area to redress this. Thus, BAS is invaluable in providing information allowing comparisons to be made, whilst the maps themselves allow for more informed decision making.

In terms of further research, CBBE may be studied over time by changes in BAS that result from planned marketing activity (sponsorship, new advertising etc.) and uncontrolled events (good/bad publicity). Such longitudinal analysis promises to provide insight on how best to communicate brand messages and meaning for strengthening brand associations. Thus we can assess how effective any given marketing strategy is at building brand equity (in terms of BAS).

With regards the BAS measure itself, there is more to be done. Space prohibits it here but, having arrived at a score of BAS, further research could seek to develop a normalised score to allow the relative strength of brand associations to be ascribed to a given map. This would allow the brand to be placed on a scale between a maximum of 1 (all associations interlinked and with a weighting of 3 
for each link) and a figure approaching 0 (with few linkages of a weighting of 1 for each link). From this, a brand may be evaluated in terms of its relative position to a perfectly strong/weak brand. It would also allow brands from the same and different product categories to be compared comparing normalised BAS scores for McDonald’s with Burger King has clear relevance for competitive analysis. Comparing McDonald’s BAS with Nike allows for a broader brand value analysis and the ranking of BAS for brands across different product markets. Lesser known brands may also be researched in this way. Inevitably, they will tend to have fewer associations, fewer links between associations and these links will tend to be relatively weak. As expected, these factors would result in diminished BAS values. Thus, the approach presented in this paper is applicable to any brand.

With regards limitations, although a key element, brand association strength, does not comprehensively measure brand equity. Dacin and Smith (1994) postulated that brand associations must be strong but also favourable for brand equity enhancement. The McDonald's maps reveal a complex structure with favourable and unfavourable associations present (as has been seen for other brands (French and Smith, 2010)). Krishnan (1996) has suggested that the valence of associations be measured as net favourability (positive versus negative scores as applied directly on maps by respondents) and this refinement needs developing for wider analysis of brand maps where both positive and negative associations may exist (e.g. for HSBC, BP, Starbucks, etc.). As such there is further research potential to develop a measure building on BAS that incorporates measures of favourability and uniqueness to arrive at a more unified measure of CBBE. The BCM approach could be used to capture these extra dimensions and network analysis techniques employed to integrate them.

Analyzing CBBE via brand associations using concept maps is at an early stage of its development, but offers many interesting opportunities for further research. In so doing we will develop our knowledge of how brand equity is constructed and, ultimately, provide a much clearer way of measuring how consumers, through the associations they hold in memory, add value to any given brand.

\section{References}

Aaker, D. (1991), Managing Brand Equity, The Free Press, New York. 
Aaker, D. (1996a), “Measuring brand equity across products and markets”, California Management Review; Vol. 38, No. 3, pp. 102-120.

Aaker, D. (1996b), Building Strong Brands, The Free Press, New York.

Ahn, W. (1998), "Why are Different Features Central for Natural Kinds and Artifacts? The Role of Causal Status in Determining Feature Centrality”, Cognition, Vol. 69, pp. 135-178.

Ailawadi, K.L., Lehmann, D.R. and Neslin, S.A. (2003), "Revenue Premium as an Outcome Measure of Brand Equity”, Journal of Marketing, Vol. 67, No. 4, pp. 1-17.

Alba, J.W., Hutchinson, J.W. and Lynch, J.G. (1991), “Memory and Decision Making”, in Robertson, T.S. and Kassarjian, H.H. (Eds.), Handbook of Consumer Behavior, Prentice-Hall, Englewood Cliffs, New Jersey, pp. 1-49.

Ambler, T. (2003), Marketing and the Bottom Line: Creating the Measures of Success. Financial Times/Prentice Hall, London.

Anderson, J.R. and Bower, G.H. (1973), Human Associative Memory, Erlbaum, Hillsdale, New Jersey.

Anderson, J.R. (1983a), The Architecture of Cognition, Harvard University Press, Cambridge, Massachusetts.

Anderson, J.R. (1983b), “A Spreading Activation Theory of Memory”, Journal of Verbal Learning and Verbal Behaviour, Vol. 22, pp. 261-295.

Calder, B.J., Phillips L.W. and Tybout, A.M. (1981), “Designing Research for Application”, Journal of Consumer Research, Vol. 8, No. 2, pp. 197-207.

Chaudhuri, A. and Holbrook, M.B. (2001), “The Chain of Effects from Brand Trust and Brand Affect to Brand Performance: The Role of Brand Loyalty”, Journal of Marketing, Vol. 65, No. 2, pp. 81-93.

Christodoulides, G. and de Chernatony, L. (2010), “Consumer-based brand equity conceptualisation 
and measurement: a literature review”, International Journal of Market Research, Vol. 52, No. 1, pp. 43-66.

Dacin, P.A. and Smith, D.C. (1994), "The Effect of Brand Portfolio Characteristics on Consumer Evaluations of Brand Extensions,” Journal of Marketing Research, Vol. 31, May, pp. 229-42.

del Río, A.B., Vázquez, R. and Iglesias, V. (2001), “The effects of brand associations on consumer response”, Journal of Consumer Marketing, Vol. 18, No. 5, pp. 410 - 425.

Dobni, D., \& Zinkhan, G.M. (1990). "In search of brand image: A foundation analysis”, Advances in Consumer Research, Vol. 17, pp. 110-119.

Erdem, T. (1998), “An Empirical Analysis of Umbrella Branding”, Journal of Marketing Research, Vol. 35, No. 3, pp. 339-351.

Erdem, T., Swait, J., Broniarczyk, S., Chakravarti, D., Kapferer, J-N., Keane, M., Roberts, J., Steenkamp, J-M. and Zettelmeyer, F. (1999), “Brand Equity, Consumer Learning and Choice”, Marketing Letters, Vol. 10, No. 3, pp. 301-318.

Farquhar, P.H. (1989), “Managing Brand Equity”, Marketing Research, Vol. 1, No. 3, pp. 24-33.

French, A.P. and Smith, I.G. (2010), “Measuring Political Brand Equity: A Consumer Oriented Approach”, European Journal of Marketing, Vol. 44, No. 3/4, pp. 460-477.

Gower, J, Groenen, P., Van de Velden, M. and Vines, K. (2010), "Perceptual Maps: The Good, the Bad and the Ugly “, ERIM Report Series, No. ERS-2010-011-MKT, http://ssrn.com/abstract=1572196 (accessed 03/08/2010).

Haugtvedt, C.P., Leavitt, C. and Schneier, W.L. (1993), “Cognitive Strength of Established Brands: Memory, Attitudinal and Structural Approaches”, in Aaker, D. and Biel, A., (Eds.), Brand Equity and Advertising, Lawrence Erlbaum Associates, New Jersey, pp. 247-262.

Henderson G., Iacobucci D. and Calder B.J. (1998), "Brand Diagnostics: Mapping Branding Effects Using Consumer Associative Networks”, European Journal of Operational Research, Vol. 111, No. 
2, pp. 306-327.

Henderson, G., Iacobucci, D. and Calder, B.J. (2002), “Using network analysis to understand brands”, Advances in Consumer Research, Vol. 29, pp. 397-405.

Iacobucci, D. and Hopkins, N. (1992), “Modeling Dyadic Interactions and Networks in Marketing”, Journal of Marketing Research, Vol. 29, No. 1, pp. 5-17.

Iacobucci, D., Henderson, G., Marcati, A. and Chang, J.E., (1996), “Networks analysis of brandswitching behavior”, International Journal of Research in Marketing, Vol. 13, pp. 415-429

John, D.R., Loken, B., Kim, K. and Basu Monga, A. (2006), “Brand Concept Maps: A Methodology for Identifying Brand Association Networks”, Journal of Marketing Research, Vol. 43, No. 4, pp. 549-563.

Joiner, C. (1998), “Concept Mapping in Marketing: A Research Tool for Uncovering Consumers' Knowledge Structure Associations”, Advances in Consumer Research, Vol. 25, No. 1, pp. 311-17.

Keller, K.L. (1993), “Conceptualizing, measuring, and managing customer-based brand equity”, Journal of Marketing, Vol. 57 No.1, pp.1-22.

Keller, K.L. (2002), “Branding and Brand Equity”, in Weitz, B.A. and Wensley, R., (Eds.), Handbook of Marketing, Sage, London, pp. 151-178.

Keller, K.L. (2003), “Brand Synthesis: The Multidimensionality of Brand Knowledge”, The Journal of Consumer Research, Vol. 29, No. 4, pp. 595-600.

Keller, K.L. and Lehmann, D. (2006), "Brands and Branding: Research Findings and Future Priorities”, Marketing Science, Vol. 25, No. 6, pp. 740-759.

Kirmani, A., Sood, S. and Bridges, S. (1999), “The ownership effect in consumer responses to brand line stretches”, Journal of Marketing, Vol. 63, January, pp. 88-101.

Knoke, D. and Yang, S. (2008), Social Network Analysis, Sage, Los Angeles.

Krishnan, S.H. (1996), “Characteristics of Memory Associations: A Consumer-Based Brand Equity 
Perspective”, International Journal of Research in Marketing, Vol. 13, 389-405.

Low, G.S. and Lamb, C.W. (2000), “The measurement and dimensionality of brand associations”, Journal of Product and Brand Management, Vol. 9, No. 2, pp. 350-368.

Netemeyer, R.G., Krishnan, B., Pullig, C., Wang. G., Yagci, M., Dean, D., Ricks, J. and Wirth, F., (2004), "Developing and validating measures of facets of customer-based brand equity”, Journal of Business Research, Vol. 57, No. 2, pp. 209-224.

Pappu, R., Quester, P.G. and Cooksey, R.W., (2006), “Consumer-Based Brand Equity and Countryof-Origin Relationships”, European Journal of Marketing, Vol. 40, No. 5/6, pp. 696-717

Rego, L.L., Billett, M.T. and Morgan, N.A. (2009), “Consumer-Based Brand Equity and Firm Risk”, Journal of Marketing, Vol. 73, No. 6, pp. 47-60.

Scott, J. (2000), Social Network Analysis: A Handbook, $2^{\text {nd }}$ ed., Sage, London.

Teichert, T.A. and Schöntag, K. (2010), “Exploring Consumer Knowledge Structures Using Associative Network Analysis”, Psychology \& Marketing, Vol. 27(4), pp. 369-398.

van Rekom, J., Jacobs, G. and Verlegh, P.W.J. (2006), “Measuring and managing the essence of a brand personality”, Marketing Letters, Vol. 17, 181-192.

Ward, J.C. and Reingen, P.H. (1990), "Sociogognitive Analysis of Group Decision Making among Consumers", Journal of Consumer Research, Vol. 17, December, pp. 245-262.

Wasserman, S. and Faust, K. (1994), Social Network Analysis: Methods and Applications, Cambridge University Press, Cambridge.

Wyer, R.S. and Srull, T.K. (1989), “Person memory and judgement”, Psychological Review, Vol. 96, No. 1 , pp. 58-83. 


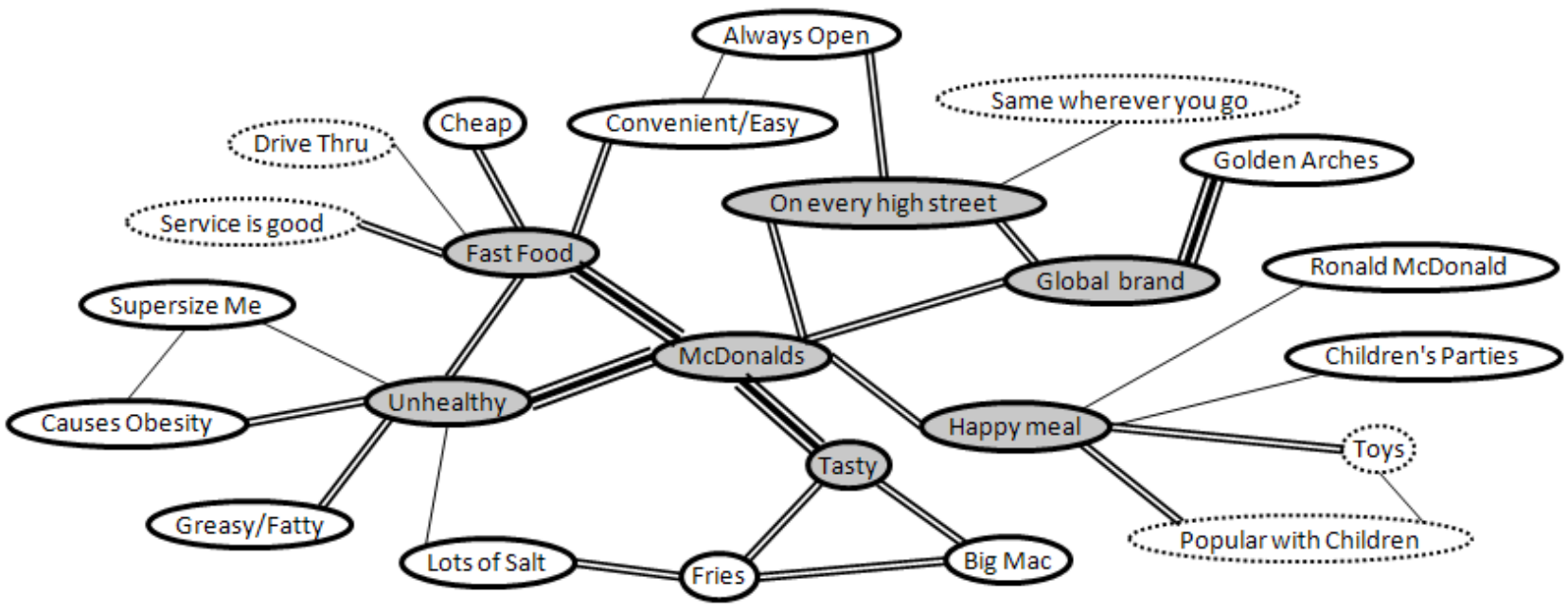

Figure 1. Brand Concept Map of McDonald's: Positive Attitude Respondents

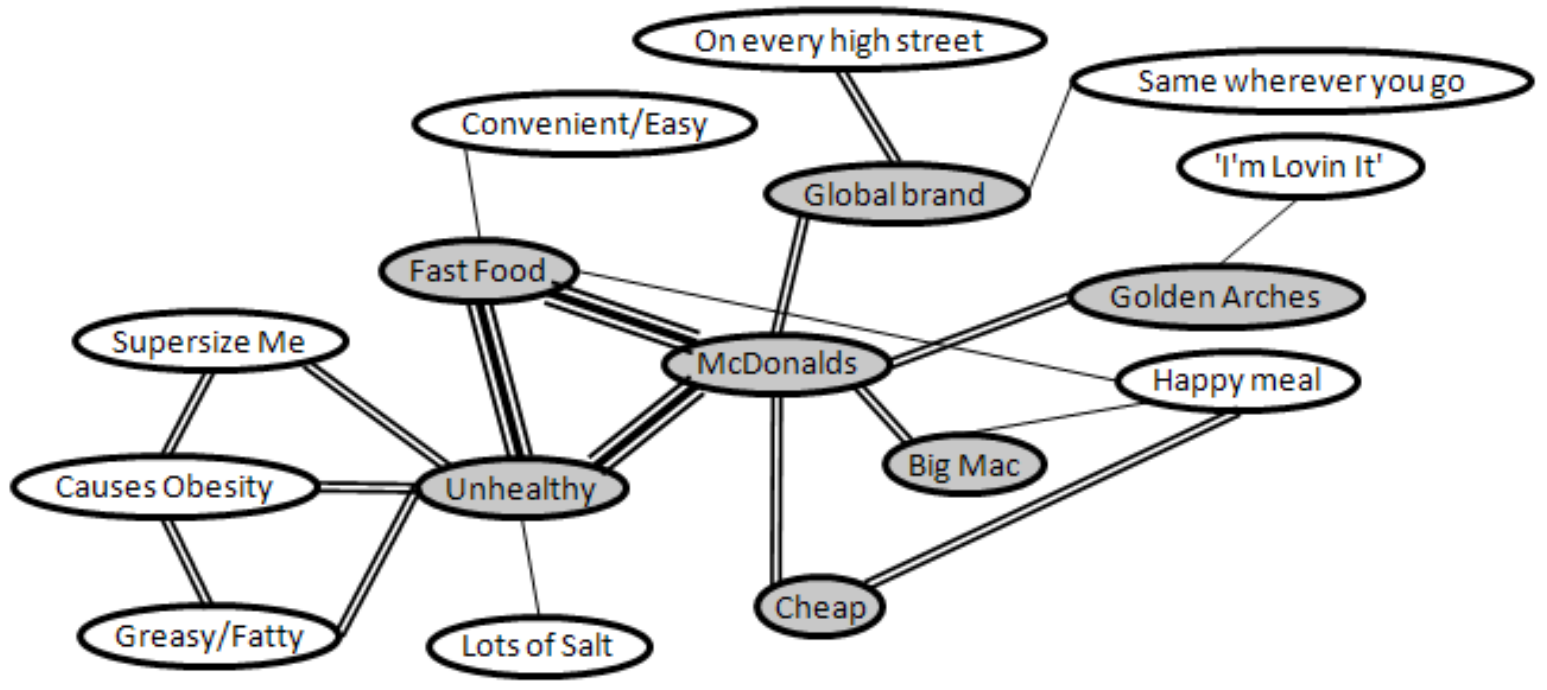

Figure 2. Brand Concept Map of McDonald's: Negative Attitude Respondents 